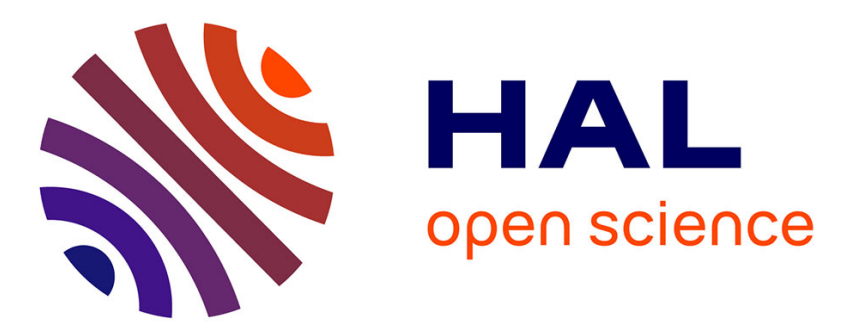

\title{
One-Step Introduction of Broad-Band Mesoporosity in Silica Particles Using a Stimuli-Responsive Bioderived Glycolipid
}

\author{
Bejoy Thomas, Florence Babonneau, Thibaud Coradin, Inge N. A. van \\ Bogaert, Niki Baccile
}

\section{To cite this version:}

Bejoy Thomas, Florence Babonneau, Thibaud Coradin, Inge N. A. van Bogaert, Niki Baccile. One-Step Introduction of Broad-Band Mesoporosity in Silica Particles Using a Stimuli-Responsive Bioderived Glycolipid. ACS Sustainable Chemistry \& Engineering, 2014, 2 (3), pp.512-522. 10.1021/sc400443g . hal-01137452

\section{HAL Id: hal-01137452 https://hal.sorbonne-universite.fr/hal-01137452}

Submitted on 3 Feb 2017

HAL is a multi-disciplinary open access archive for the deposit and dissemination of scientific research documents, whether they are published or not. The documents may come from teaching and research institutions in France or abroad, or from public or private research centers.
L'archive ouverte pluridisciplinaire HAL, est destinée au dépôt et à la diffusion de documents scientifiques de niveau recherche, publiés ou non, émanant des établissements d'enseignement et de recherche français ou étrangers, des laboratoires publics ou privés. 


\title{
One-step introduction of broad-band mesoporosity in silica particles using a stimuli-responsive bio-derived glycolipid
}

\author{
Authors \\ Bejoy Thomas, ${ }^{\mathrm{a}, \mathrm{b}, \mathrm{c}, \mathrm{d}}$ Florence Babonneau, ${ }^{\mathrm{a}, \mathrm{b}, \mathrm{c}}$ Thibaud Coradin,, ${ }^{\mathrm{a}, \mathrm{b}, \mathrm{c}}$ Inge N. A. Van Bogaert ${ }^{\mathrm{e}}$, Niki \\ Baccile $^{\mathrm{a}, \mathrm{b}, \mathrm{c} *}$
}

\begin{abstract}
Affiliations
a-UPMC Univ Paris 06, UMR 7574, Chimie de la Matière Condensée de Paris, F-75005, Paris, France

b- CNRS, UMR 7574, Chimie de la Matière Condensée de Paris, F-75005, Paris, France

c- Collège de France, UMR 7574, Chimie de la Matière Condensée de Paris, F-75005, Paris, France

d- Department of Chemistry, Newman College, 685 585-Thodupuzha, Kerala, INDIA

e- InBio, Department of Biochemical and Microbial Technology, Faculty of Bioscience Engineering, Ghent University, Coupure Links 653, 9000, Ghent, Belgium
\end{abstract}

\begin{abstract}
Stimuli-responsive glycolipid biosurfactants belonging to the family of acidic sophorolipids (SL) have been used to introduce a broad range of pore size in the mesoscale regime (2 nm $30 \mathrm{~nm}$ ) in silica particles using a one-pot co-assembly sol-gel route in water. The pore size distribution is tailored by the sole interaction between an amino-modified silane, aminopropyltriethoxy silane (APTES) and SL. No additional compounds (e.g., block copolymers, polymers, organic solvents, pore-swelling agents) have been used to promote the formation of mesopores larger than $2 \mathrm{~nm}$. Increase of the basicity of the medium has a strong impact on the glycolipid assembly, which is known to form large supramolecular assemblies
\end{abstract}


at high $\mathrm{pH}$. Materials morphology and porosity have been characterized by high resolution TEM, SEM and nitrogen physisorption while the interaction between the glycolipid and silica is demonstrated by FT-IR and solid state NMR.

Keywords. Porous silica. Sophorolipids. Anionic Mesoporous Silica (AMS). Aminopropyltriethoxysilane (APTES). Biosurfactants. Glycolipids.

\section{Introduction}

Porosity in materials has been deeply explored because of the large number of applications that are concerned, such as catalysis, sensing, drug delivery. In the specific field of sol-gel chemistry, this task is nowadays mastered by the well-known bottom-up templating process that can provide, among others, gels, powders, thin films and fibrous shaped materials. ${ }^{1,2,3}$ Independently of the scale of porosity (micro $<2 \mathrm{~nm}$, meso between 2 and 50 $\mathrm{nm}$ and macro, above $50 \mathrm{~nm}$ ), recent research works have been focused on developing methods to achieve a three-dimensional, long-range, organisation of the pores of different sizes. Hierarchy in size and pore interconnection have been judged to be equally, if not more, important in terms of final application because of the much easier control that one can establish on the diffusion properties inside the pores. ${ }^{4,5,6}$ Typically, organic templates are currently used to obtain micro- or meso-scale porosity such as in zeolites (use of quaternary ammonium salts) or in MCM-41 or SBA-15 materials (use of surfactant micelles). ${ }^{7,8}$ Ordered macroporosity is easily achieved using micrometer-sized colloidal packing. The main idea behind each templating process is that the pore size is strongly related to the size of the template, if one does not consider any additional effect driven by thermal treatment or use of organic swelling agents. ${ }^{4,9,10,}$ Other typical porogens can be: colloids, emulsions, gases, vesicles, salts, water, polymers and a wide combination of these to eventually achieve a hierarchical porous network. ${ }^{11,12}$ Removal of the template takes place with soxhlet washing, calcination or other techniques based on the stimuli-driven dissociation of coacervates. ${ }^{13,14}$ If sustainability is taken as an important criterion in the synthesis process, the number of works is drastically reduced. A recent review paper nicely outlines all possible sustainable ways to obtain mesoporous oxides, and use of bio-sourced porogenic agents was shown to be an important issue with a limited amount of work. ${ }^{15}$

In this context, we have recently investigated the self-assembly and structuring properties of sophorolipids (SL), a family of entirely bio-derived glycolipids. ${ }^{16,17,18}$ These natural compounds are obtained in large amounts (several hundred gram per liter) by yeast 
culture in presence of several carbon sources, like glucose, fatty acids but even alkanes and waxes. ${ }^{19}$ Due to their biosynthesis with reduced environmental impact, confirmed by a recent life cycle analysis study, ${ }^{20}$ sophorolipids (SL) have attracted a fair attention of the home and skin-care industry ${ }^{21}$ even if other applications are being explored, as antimicrobial ${ }^{22}$ and anticancer $^{23}$ agents, surface stabilizer for nanoparticles. ${ }^{24}$ More specifically, their selfassembly properties are being explored with particular interest ${ }^{16,19 d, 25,26}$ and in the context of drug release, an ongoing work in our group puts in relationship the silica templating properties of self-assembled sophorolipids and their eventual controlled release in solution. ${ }^{27}$ Acidic SL, which contain a free $\mathrm{COOH}$ group, are also of particular interest because of the pH-dependent self-assembly behaviour. ${ }^{16,19 \mathrm{~d}}$ In particular, the size of the supramolecular aggregates strongly increases from acidic to basic $\mathrm{pH}$. We have also used them as structuredirecting agents in the formation of silica thin films using the evaporation induced selfassembly (EISA) process. We could then show the formation of silica thin films exhibiting a wormlike organization of the pore but, more importantly, their size strongly increases with pH. ${ }^{16}$

In the present work, we discuss the templating and porogenic effect of SL in the synthesis of silica powders obtained by the precipitation technique in water. The process of self-assembly in solution is driven by the organic/inorganic interactions between the surfactant and the silicate species. This effect is largely observed in the synthesis of MCM and SBA-type materials, where direct (MCM-41), indirect (SBA-3) electrostatic or hydrogen bond (SBA-15) interactions drive the precipitation of mesostructured silica powders with long-range order. ${ }^{28}$ Sophorolipids in water practically behave as non-ionic compounds and they can be associated to the most common polyethylene oxide based surfactants, precursors of SBA-15 materials. However, when sophorolipids are used as structure directing agents under the typical conditions (acidic water solution) required to form these materials, a gel is systematically obtained. This is a strong hint that the interactions between sophorose, the main hydrophilic moiety of SL, and silica oligomers in solution are not strong enough to trigger silica condensation. Nevertheless, SL contain a $\mathrm{COOH}$ group, the role of which in their self-assembly has been described previously, ${ }^{17}$ making them effectively anionic amphiphiles. It is then possible to employ the structuring strategies commonly used for the synthesis of Anionic surfactant templated Mesoporous Silicas (AMSs), based on charge matching between anionic surfactants with an amino-modified silane, (e.g., APTES), ${ }^{14,29,30}$ a co-reactant in the formation of a hybrid organic-inorganic silica scaffold. 
We are able here to go one step further because the $\mathrm{NH}_{2} / \mathrm{SL}$ ratio also influences the nature of the $\mathrm{pH}$-sensitive sophorolipids assemblies, ${ }^{17,18}$ having a strong impact on the final mesoporous texture. The final pore size distribution varies between 3 and $30 \mathrm{~nm}$, suggesting the formation of SL large aggregates. Interestingly, in this specific case, a biomodal pore size distribution can be achieved, with larger pores being accessible without removal of the template. Our results demonstrate that it is possible to use a single type of bioderived surfactant to obtain comparable porosity to what can be obtained by mixing two different surfactants, such as CTAB and a polyethylene oxide-based block copolymer, ${ }^{4}$ thus showing that the sustainability principles in the synthesis of porous oxides ${ }^{15}$ can be successfully put to practice.

\section{Experimental}

All products (excluding sophorolipids) used in this work were purchased from Aldrich. Raw sophorolipids were produced by Starmerella bombicola (ATCC 22214). They have been eventually hydrolyzed to obtain only acidic sophorolipids (SL), as described elsewhere. ${ }^{16,17}$

Silica particles synthesis procedures have been adapted from ref. 30. Samples SL1 and SL2: a specific amount of SL (0.390 g for SL1 and $0.456 \mathrm{~g}$ for SL2) was dissolved in $20 \mathrm{~g}$ of water of MilliQ purity under stirring at room temperature overnight. The system is then brought to $60^{\circ} \mathrm{C}$ under stirring and under these conditions, $0.484 \mathrm{~g}$ of (3-aminopropyl)triethoxysilane (APTES) were introduced, immediately followed by $1.004 \mathrm{~g}$ of tetraethyl orthosilicate (TEOS); this was kept under static conditions for $12 \mathrm{~h}$ at $60^{\circ} \mathrm{C}$. The batch was eventually treated under static hydrothermal conditions for $6 \mathrm{~h}$ at $100^{\circ} \mathrm{C}$. The powder was collected by filtration, washed with distilled water and air-dried. For sample SL3, a similar protocol was followed except that $1.351 \mathrm{~g}$ of SL were introduced in $45 \mathrm{~g}$ of water of MilliQ purity and a larger amount of TEOS (1.808 g) was used, the amount of APTES being constant. The $S L$ free sample was obtained using the same synthesis procedure as for SL1 and SL2, but no SL was added. Relative molar concentrations are summarized in Table 1.

A two-step calcination procedure was used for organics removal. The sample is initially kept at $300^{\circ} \mathrm{C}$ for $2 \mathrm{~h}$ before the final treatment at $500^{\circ} \mathrm{C}$ for $5 \mathrm{~h}$ under air. Heating rate is $2^{\circ} \mathrm{C} / \mathrm{min}$.

Table 1 - Molar ratio of samples SL1, SL2 and SL3. The [Si] column refers to the contribution of both TEOS and APTES. The [ $\left.\mathrm{NH}_{2}\right]$ column refers to the contribution of APTES alone

\begin{tabular}{|l|l|l|l|}
\hline Sample & SL & {$[\mathrm{Si}]$} & {$\left[\mathrm{NH}_{2}\right]$} \\
\hline
\end{tabular}




\begin{tabular}{|l|c|c|c|}
\hline SL1 & 1 & 11.2 & 3.5 \\
\hline SL2 & 1 & 9.6 & 2.3 \\
\hline SL3 & 1 & 5.0 & 1.0 \\
\hline
\end{tabular}

\section{Experimental techniques.}

Transmission Electron Microscopy (TEM) was run on a FEI Tecnai 120 Twin microscope operating at $120 \mathrm{kV}$ and equipped with a high resolution Gatan Orius CCD 4k x 4k numeric camera while Scanning Electron Microscopy (SEM) was done on a Hitachi S3400N instrument while SEM Field Emission Gun (SEM-FEG) was done on Hitachi SU-70 instrument at the Institut des Matériaux de Paris Centre (IMPC) facilities. Particle size distribution was calculated from SEM images using Image ${ }^{31}$ software. Elemental analysis (C, $\mathrm{N})$ was performed at the Microanalysis Center of the Université Pierre et Marie Curie (France). Small angle X-ray scattering (SAXS) measurements on powder samples were performed on a pinhole type S-MAX 3000 RIGAKU Nanoviewer instrument using a monochromatic $\mathrm{Cu}-\mathrm{K} \alpha$ radiation and equipped with a $\mathrm{CCD}$ detector. The sample-to-detector distance was $0.059 \mathrm{~m}$. The applied voltage and filament current were $40 \mathrm{kV}$ and $50 \mathrm{~mA}$ respectively. ThermoGravimetric Analysis (TGA) was run on a Netzsch STA 409 PC Luxx instrument using a $5^{\circ} \mathrm{C} / \mathrm{min}$ heating rate. Fourier-Transform Infra-Red (FT-IR) spectroscopy has been operated on a Perkin Elmer 400 spectrometer using the universal ATR sampling holder.

Adsorption/desorption isotherms were recorded on a Belsorp-Max Instrument (BELJapan Inc.) using nitrogen as probe gas. $t$-plot analysis was performed on the basis of an empirical mathematical expression based on adsorption measurements obtained on model materials, as detailed in the supplementary information material in section S1.0 and in corresponding Figure S1 and Figure S2.

${ }^{13} \mathrm{C}\left\{{ }^{1} \mathrm{H}\right\}$ Cross-Polarization (CP) Magic Angle Spinning (MAS) solid-state Nuclear Magnetic Resonance (NMR) experiments were performed on a Bruker AVANCE III 300 (7.05 T) spectrometer using a wide-bore superconducting magnet and a $4 \mathrm{~mm}$ MAS probe at a spinning frequency of $14 \mathrm{kHz}$. A cross-polarization contact time, $\mathrm{t}_{\mathrm{c}}$, of $3.0 \mathrm{~ms}$, a relaxation delay of $3 \mathrm{~s}$ and 8192 transients were applied for all the experiments. One pulse ${ }^{29} \mathrm{Si}$ MAS NMR studies were run on Bruker AVANCE III 500 (11.75 T) spectrometer employing a 7 mm zirconia rotors spinning at $5 \mathrm{kHz}$. A total of 240 transients were collected using a $\pi / 4$ pulse and a relaxation delay of $60 \mathrm{~s}$. The chemical shift values were calibrated with reference to tetramethylsilane (TMS) at $0 \mathrm{ppm}$. The ${ }^{13} \mathrm{C}\left\{{ }^{1} \mathrm{H}\right\}$ CPMAS two-dimensional HETero CORrelation (HETCOR) experiments were performed on a Bruker AVANCE III 700 (16.45 
T) spectrometer using a $3.2 \mathrm{~mm}$ rotor spinning at $22 \mathrm{kHz}$, where recycle delay is $3 \mathrm{~s}$ and $\mathrm{t}_{\mathrm{c}}=$ $0.5 \mathrm{~ms}$, which was chosen to explore short-range carbon-proton proximities. Two-pulse phase-modulated (TPPM) proton decoupling was applied during acquisition while quadrature detection in $t_{1}$-dimension was realized using the STATES method. Cross-polarization transfers have been optimized under adiabatic tangential ramps. ${ }^{32,33}$

\section{Results and discussion}

Sophorolipid-containing porous silica powders can be readily synthesized in the presence of APTES, the role of which is of being a promoter of the interaction between the amino group and the carboxylate in SL, thus driving the precipitation phenomenon. Described below is the specific analysis of these APTES-containing silica materials obtained at different $\mathrm{NH}_{2} / \mathrm{SL}$ ratio.
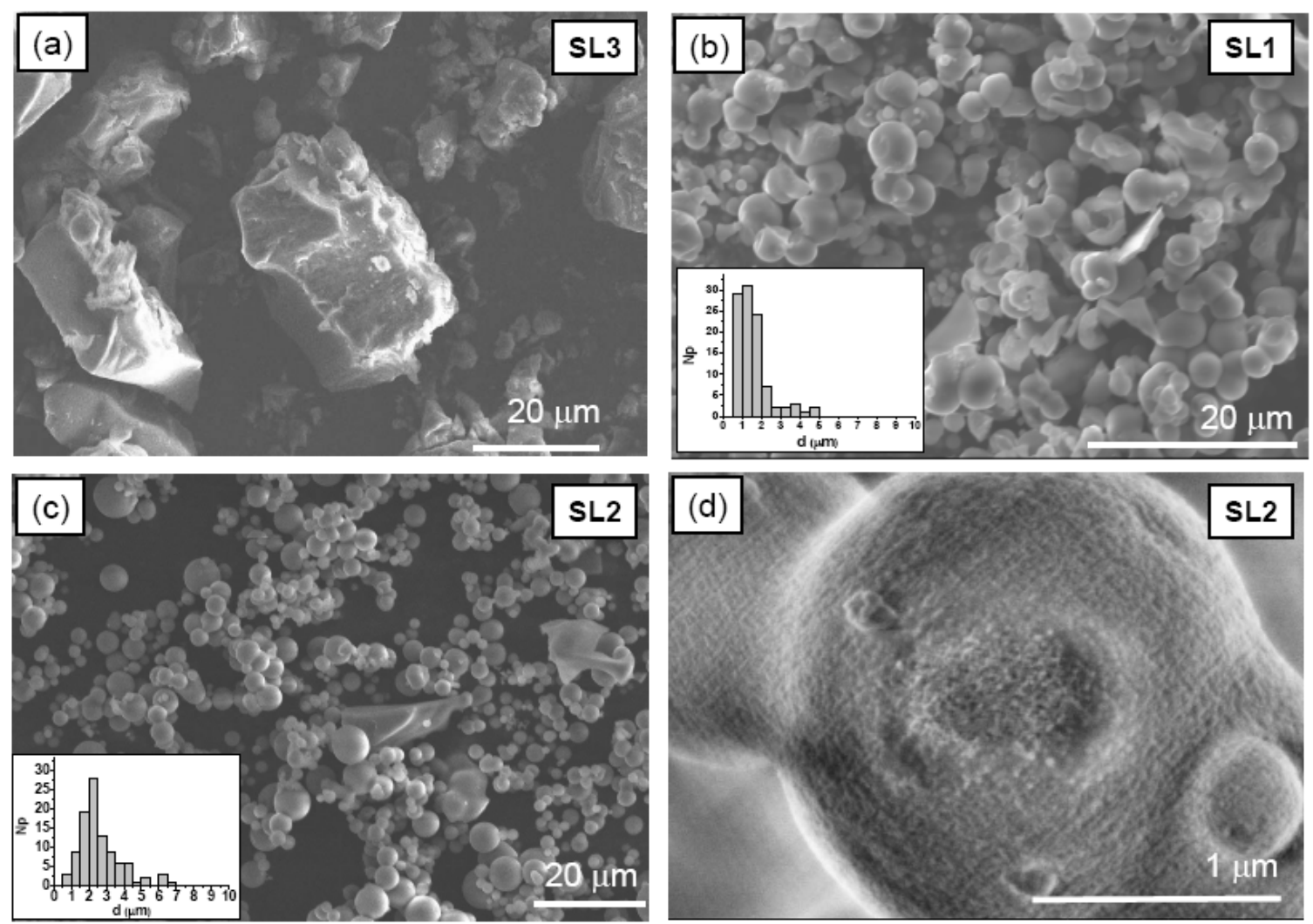

Figure 1. SEM pictures of samples a) SL3, b) SL1and c,d) SL2. Image (d) is obtained using a Field Emission Gun (FEG) SEM microscope.

\section{Electron microscopy studies}

In Figure 1 SEM images of the SL3 (a), SL1 (b) and SL2 (c,d) powder samples are shown. SL1 and SL2 samples are mostly composed of spherical micrometer-sized particles, the size distributions of which, obtained from direct counting on the SEM figures, are shown 
in the insets. SL1 shows particles having a log-normal distribution with a modal diameter centered at about $1.5 \mu \mathrm{m}$ while SL2 particles show rather a Gaussian distribution having an average diameter of $2.5 \mu \mathrm{m}$. As for the SL3 sample, very few spherical particles are observed and the material is mainly constituted by amorphous micrometer-scale blocks. Figure 1d shows a magnified image of sample SL2 obtained using a high resolution Field Emission Gun (FEG) SEM microscope. This image shows a developed roughness and a nanoscale porosity, which characterizes the entire outer surface of the particle. This result is confirmed by TEM imaging of SL1 and SL2 samples, shown in Figure 2 a-d as it shows the existence of an interconnected and apparently accessible porosity over the whole particle volume. A closer look at SL1 sample (Figure 2c) evidences the presence of 10-20 nm sized interconnected particles constituting the larger spheres. When SL is not added to the precursor solution, the obtained powdery material is constituted by sub-micrometer sized amorphous particulate that does not display any porosity. This is in agreement with previous observations of APTEScatalyzed silica particles ${ }^{34}$ and indicates that the here-obtained morphologies cannot be attributed to APTES only. It is important to note that small angle X-ray diffraction (not shown here), typically employed to put in evidence a long-range mesoscopic order, did not provide any indication for any special organization of the porous network, as one would expect for typical surfactant-derived silica solids and as previously found for EISA-derived sophorolipid-based silica thin films. ${ }^{16}$ 

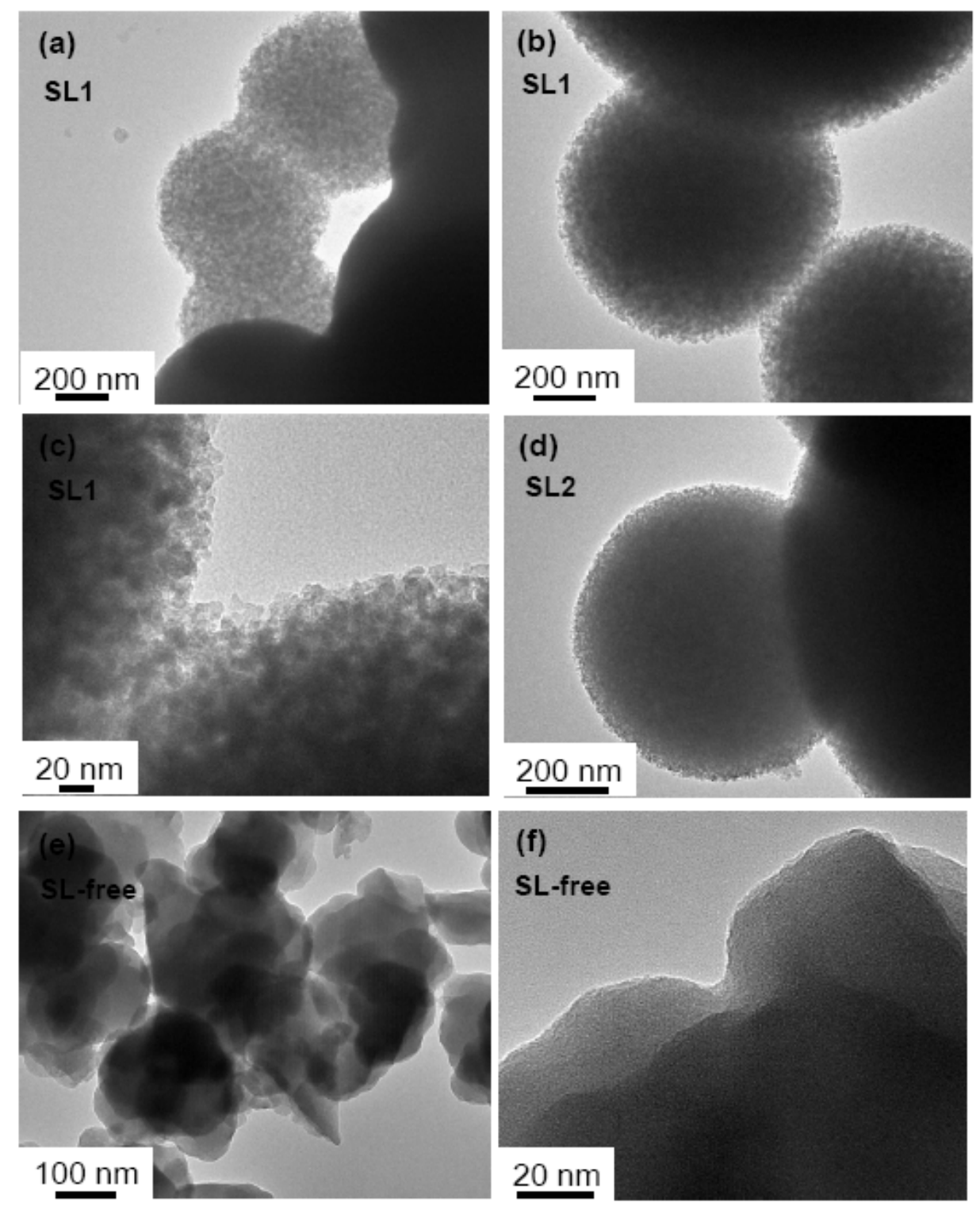

Figure 2 - TEM images a-c) SL1, d) SL2 and e-f) sophorolipid-free (SL-free) silica samples

\section{Specific surface area and porosimetry analysis}

Despite the lack of long-range organization of the pores, the most interesting feature to put in evidence is the apparent porosity of the materials in the absence of a calcination step. $\mathrm{N}_{2}$ adsorption/desorption isotherms presented for the as-synthesized (Figure 3a) and calcined (Figure 3c) SL1, SL2, SL3 and SL-free samples supports this assumption in a direct way. First of all, the isotherm related to the SL-free sample indicates the absence of pores larger than $2 \mathrm{~nm}$ before and after thermal treatment, which is consistent with the TEM image (Figure 2 e,f), and typical of a dense material. However, microporosity is detected after calcination (sharp nitrogen uptake at $\mathrm{P} / \mathrm{P}_{0}<0.01$ ). As for sample SL3, the isotherms recorded for the assynthesized and calcined samples reflect the typical behaviour of an organically-templated mesoporous network, where porosity is not accessible before template removal whereas a 
well-defined type-IV isotherm with a H2 hysteresis loop is observed upon calcination. This is characteristic for a complex network of interconnected pores of different shapes and sizes. ${ }^{35}$ On the contrary, SL1 and SL2 samples show a well-defined type IV isotherm with a H3 hysteresis loop before any template removal (Figure 3a). Upon calcination, small-scale porosity becomes accessible, as demonstrated by the increase in the adsorbed volume at low $\mathrm{P} / \mathrm{P}_{0}<0.1$. In parallel, the shape of the isotherm at higher relative pressure $\left(\mathrm{P} / \mathrm{P}_{0}>0.5\right)$ is almost not affected by the calcination step for both samples. A closer look at the $\mathrm{N}_{2}$ isotherms and corresponding BJH plots for SL1 and SL2 are provided in Figure S3, where the isotherm for the as-synthesized SL2 sample has been multiplied by a factor 2 for convenience. The change in the isotherm shape, and consequently of the adsorption behaviour, is mild at high relative pressure. For SL1 (Figure S3a), the shape of the hysteresis loop is very similar before and after calcination with two desorption steps at $\mathrm{P} / \mathrm{P}_{0}=0.44$ and 0.85 . After calcination, desorption above $\mathrm{P} / \mathrm{P}_{0}>0.7$ is practically unchanged while the desorbed volume at $\mathrm{P} / \mathrm{P}_{0}=0.44$ has slightly increased. The corresponding BJH pore size distribution in Figure S3c shows that the overall shape of the distribution does not change before and after calcination (especially the band at $d_{p}=20.7 \mathrm{~nm}$ ) but it actually becomes more resolved (peak at $d_{p}=12.7 \mathrm{~nm}$ ) with overall larger $d V_{p} / d \log d_{p}$ values. Since no variation in size is detected before and after calcination, these data could suggest that a fraction of the pores is filled with organic matter before calcination. For SL2, the nitrogen isotherms are slightly different before and after calcination (Figure S3b), but under both conditions one can still observe a clear hysteresis loop. As for SL1, the upper part $\left(\mathrm{P} / \mathrm{P}_{0}>0.7\right)$ of the isotherm is less influenced by the calcination step, as seen in the BJH pore size distribution (Figure S3d), in which the position of peak at $d_{p}=11.1 \mathrm{~nm}$ is not affected. Smaller pores are, however, emptied after calcination and the shape of the adsorption branch indicates a large dispersion in size, discussed in more detail later.

These data mainly indicate that calcination does not affect the size of pores larger than $8 \mathrm{~nm}$ but it only affects their overall amount and, mainly for sample SL3, their connectivity. Table 2 gathers the BET specific surface area, $\mathrm{S}_{\mathrm{BET}}$, values for all samples, before and after calcination. As expected, the as-synthesized SL1 and SL2 samples have non-zero, though small, $\mathrm{S}_{\text {BET }}$ values of 23 and $42 \mathrm{~m}^{2} \cdot \mathrm{g}^{-1}$ respectively, that increase to 136 and $367 \mathrm{~m}^{2} \cdot \mathrm{g}^{-1}$ after calcination, while $S_{\text {BET }}$ for calcined SL3 is close to $500 \mathrm{~m}^{2} \cdot \mathrm{g}^{-1}$. The SL-free sample also displays a fair surface area $\left(\mathrm{S}_{\mathrm{BET}}=240 \mathrm{~m}^{2} / \mathrm{g}\right)$ mainly due to microporosity. The effect of calcination is well-known as it contributes to remove the organic matter and gives access to the porous network. If one considers that the size of a sophorolipid molecule is not more than 
$2.5 \mathrm{~nm}$ and the corresponding micellar diameter not more than $5 \mathrm{~nm},{ }^{18}$ one also expects to measure porous properties close to those found in standard-pore MCM-41 materials. In reality, SL1 can be rather compared to either block-copolymer templated silica SBA- $15^{36}$ or large-pore CTAB-derived MCM-41, obtained after 3 days of hydrothermal treatment. ${ }^{37,38}$ On the contrary, the nitrogen adsorption features of SL2 and SL3 are closer to that of a variety of other materials obtained under different conditions: hydrothermally treated SBA-15 (pore size of $8.9 \mathrm{~nm})^{36}$, monoliths obtained by a mixture of large block copolymer F127 and furfuryl alcohol, ${ }^{39}$ silica-based materials templated using a mixture of two surfactants, CTAB and block copolymer Pluronic F127. ${ }^{4}$
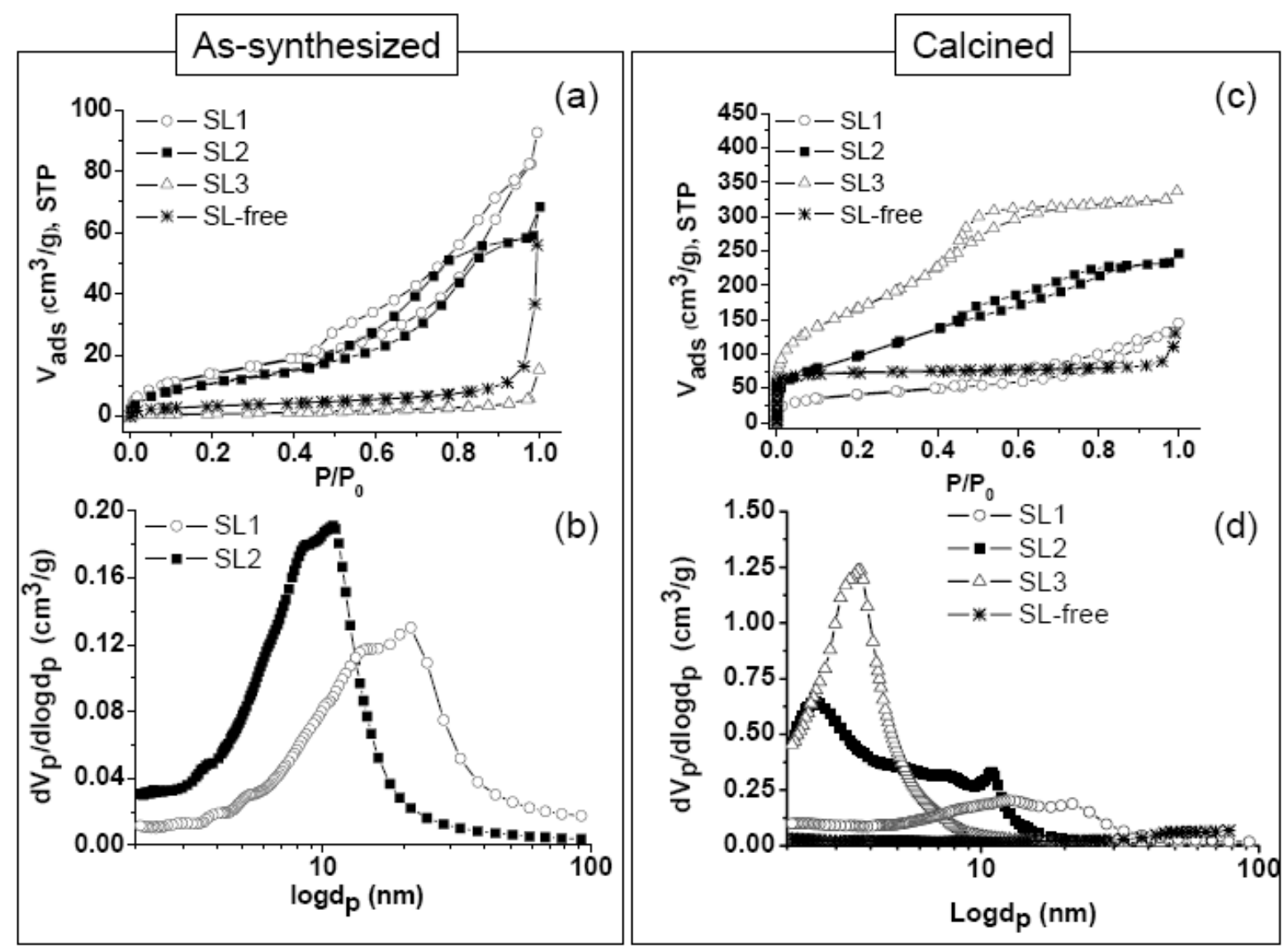

Figure $3-\mathbf{N}_{2}$ adsorption-desorption isotherms and derivate data analysis of (a-b) as synthesized and (c-d) calcined samples: (a,c) $\mathrm{N}_{2}$ isotherms; (b,d) BJH pore size distribution.

t-plot, for which standards of similar surface chemistry to our samples have been used (refer to discussion in Section S1.0), is employed here to determine the presence of microporosity. The analysis of the $t$-plot curve (section S1.0.3 in the Supplementary Information) for both as-synthesized and calcined samples (Figure S2a - Figure S2c) shows a systematic upward deviation of the $t$-curve in the mid-t region, except for the calcined SL1 sample. This behaviour is very specific of a monolayer-multilayer adsorption phenomenon 
within mesopores. ${ }^{35}$ It also indicates that microporosity, that would be indicated by a downward deviation and a consequent extrapolation of positive $V_{\text {ads }}$ value at $t=0$, is most likely absent from all samples. The only exception is constituted by the SL1 sample, in which the $t$-plot is represented by a straight line with almost no deviation. This may suggest the presence of a complex micro/mesoporous network. For this reason, the strong increase in $V_{\text {ads }}$ observed at low $\mathrm{P} / \mathrm{P}_{0}$ after calcination (Figure 3c) cannot be related to micropore-filling. Specific surface area $\left(\mathrm{S}_{\mathrm{m}}\right)$ can be directly estimated from the $t$-plot slopes in the low-pressure region and values are given in Table 2. $\mathrm{S}_{\mathrm{m}}$ is in agreement with $\mathrm{S}_{\mathrm{BET}}$, confirming that the $t$ plot analysis, and in particular the choice of the model curve, is correct.

Table 2 - Values of the specific surface areas (S), pore size (dp), specific volume (V) and fractal dimensions (FD) for samples SL1, SL2 and SL3. Subscripts refer to the method employed to obtain the value. ${ }^{\circ}$ obtained from BET analysis; * obtained from t-plot analysis; § obtained from the adsorption branch of the isotherm; \# Single-point value at $\mathrm{P} / \mathrm{P}_{0}=0.95 ; \wedge$ from $\mathrm{BJH}$ analysis;

\begin{tabular}{|c|c|c|c|c|c|c|c|c|}
\hline & Sample & $\mathrm{S}_{\mathrm{BET}^{\circ}}\left[\mathrm{m}^{2} / \mathrm{g}\right]$ & $\mathrm{S}_{\mathrm{m}} *\left[\mathrm{~m}^{2} / \mathrm{g}\right]$ & $\begin{array}{c}\mathrm{dp}^{\S} \\
{[\mathrm{nm}]}\end{array}$ & $\begin{array}{c}\mathrm{V}_{\mathrm{ads}}^{\#} \\
{\left[\mathrm{~cm}^{3} / \mathrm{g}\right]}\end{array}$ & $\begin{array}{c}\mathrm{V}_{\mathrm{ads}} \wedge \\
{\left[\mathrm{cm}^{3} / \mathrm{g}\right]}\end{array}$ & $\begin{array}{c}\mathrm{V}_{\mathrm{m}} * \\
{\left[\mathrm{~cm}^{3} / \mathrm{g}\right]}\end{array}$ & FD \\
\hline \multirow{3}{*}{ As-synthesized } & SL1 & 23 & 27 & $10 / 14 / 21$ & 0.13 & 0.11 & - & 2.4 \\
\hline & SL2 & 42 & 51 & $9 / 11$ & 0.10 & 0.11 & - & 2.4 \\
\hline & $\begin{array}{c}\text { SL3 \& } \\
\text { SL-free }\end{array}$ & - & - & - & - & - & - & - \\
\hline \multirow{4}{*}{ Calcined } & SL1 & 136 & 132 & $(8) / 12 / 21$ & 0.21 & 0.17 & - & 2.7 \\
\hline & SL2 & 367 & 338 & $3 / 7 / 11$ & 0.37 & 0.36 & 0.33 & 2.6 \\
\hline & SL3 & $599 / 478$ & 455 & $4 /(7)$ & 0.51 & 0.41 & 0.40 & 2.4 \\
\hline & SL-free & 240 & - & - & - & 0.05 & - & - \\
\hline
\end{tabular}

Figure $3 \mathrm{~b}$ and Figure $3 \mathrm{~d}$ show the pore size distribution for as-synthesized and calcined samples, respectively. As expected from the isotherms presented above, assynthesized materials are characterized by a broad distribution of pores going from 7 to 30 nm. In particular, both SL1 and SL2 show two poorly-resolved, yet detectable, maxima at 14 and $21 \mathrm{~nm}$ for SL1 (for which a shoulder at $10 \mathrm{~nm}$ can also be observed) and at 9 and $11 \mathrm{~nm}$ for SL2. Upon calcination, very similar values are still recorded for the same samples, as shown in Table 2, but a smaller pore size of $3 \mathrm{~nm}$ can additionally be seen for SL2. The presence of such small mesopores for SL2 is coherent with the conclusion drawn from $t$-plot analysis, where the presence of small mesopores instead of micropores was proposed. Finally, the pore size distribution of calcined SL3 shows a peak centered at $4 \mathrm{~nm}$ with a very sharp distribution and a broad shoulder at about $7 \mathrm{~nm}$. 
We have also evaluated the fractal dimension of the porous structure, ${ }^{35}$ as shown in Figure S2b and Figure S2d for as-synthesized and calcined samples respectively. It is known that plotting the $\log \left(\mathrm{V}_{\text {norm }}\right)$, where $\mathrm{V}_{\text {norm }}$ is the normalized specific adsorbed volume, versus $\log \left(\log \left(\mathrm{P}_{0} / \mathrm{P}\right)\right)$, where $\mathrm{P}_{0} / \mathrm{P}$ is the inverse partial pressure, one can fit the linear section of the curve in the mid $\mathrm{P}_{0} / \mathrm{P}$ region and correlate the slope to the fractal dimension (FD). FD values are comprised between 2 and 3, where 2 corresponds to a smooth surface and 3 indicates a non-regular surface, which characterizes well mid-range mesopores. For large mesopores, the explored fractal dimension belongs to the void volume that is accessible after multilayer adsorption of nitrogen. For instance FD for aerosol silica spheres has a value of 2 while FD for silica gels and aerogels is close to 3. FD for calcined MCM and SBA materials is reported to be between 2.5 and 2.7. ${ }^{40}$ Here, for as-synthesized SL1 and SL2, FD is about 2.4, while it increases to about 2.7 after calcination, indicating that internal surface roughness is already present before calcination and therefore confirming the high-resolution SEM and TEM images.

\section{Sophorolipid/silica interactions}

Considering that SL1 and SL2 show significant porosity before calcination, one can wonder about the presence of sophorolipids in the materials. Figure 4 gathers a series of complementary analytical tools used to identify and quantify sophorolipids for each sample. TGA (Figure 4a) indicates that the total organic content is no more than $10 \mathrm{wt} \%$ for SL1, and increases up to $17 \mathrm{wt} \%$ and $24 \mathrm{wt} \%$ for SL2 and SL3, respectively. From elemental analysis $(\mathrm{N}, \mathrm{C})$ the $\mathrm{NH}_{2} / \mathrm{SL}$ molar ratio in the final material is calculated, increasing from ca. 2.5 to a maximum of ca. 9.5 from SL3 to SL1. Quantitative ${ }^{29}$ Si single pulse solid state NMR spectra shown in Figure S4 allows the calculation of the T/Q ratio, where $\mathrm{T}$ species include all $\mathrm{RSiO}_{\mathrm{x}}(\mathrm{OH})_{3-\mathrm{x}}$ units $\left(\mathrm{R}=\right.$ aminopropyl) and $\mathrm{Q}$ corresponds to $\mathrm{SiO}_{\mathrm{x}}(\mathrm{OH})_{4-\mathrm{x}}$ species. If all initially added aminopropyl groups were present in the final material, T/Q value should be 0.45. In the absence of sophorolipids (SL-free sample), $\mathrm{T} / \mathrm{Q}=0.34$ while $\mathrm{T} / \mathrm{Q}=0.30$ for both SL1 and SL2. This shows that the incorporation of APTES precursors in the silica network is not complete, whether SL are present or not, in agreement with previous reports, where similar T/Q values are found. ${ }^{41}$ Finally, TGA, elemental analysis and ${ }^{29} \mathrm{Si}$ solid state NMR data indicate that the highest amount of $\mathrm{SL}$ is found in SL3, the $\mathrm{NH}_{2} / \mathrm{SL}$ ratio being the lowest among the three samples and close to 2 .

It is now possible to attempt to correlate silica morphology and porous structure with the $\mathrm{NH}_{2} / \mathrm{SL}$ ratio. We recently have deeply studied the effect of basic $\mathrm{pH}$ on the self-assembly 
of sophorolipids and, in particular, specifically observed the effect of both strong $(\mathrm{NaOH}$, $\left.\mathrm{pK}_{\mathrm{b}}=0.2\right)$ and weak $\left(\mathrm{NH}_{3}, \mathrm{pK}_{\mathrm{b}}=4.75\right)$ bases in solution. ${ }^{17,18}$ In the presence of a large excess of $\mathrm{NaOH}$ with respect to sophorolipids (ionization degree of 1 of the $\mathrm{COOH}$ group in the SL), large aggregates are observed in solution with respect to simple micelles, that are more stable at acidic $\mathrm{pH} .{ }^{17}$ When aqueous ammonia is used, larger amounts of the base with respect to sophorolipids are necessary to obtain similar results. In our previous work, ${ }^{18}$ the highest investigated $\mathrm{NH}_{3} / \mathrm{SL}$ ratio was 1.5 and, in that case, micelle formation was still favored over micron-scale aggregation. At higher ratios, micronic structures are generally formed instead of micelles. In this work, we use APTES, the $\mathrm{pK}_{\mathrm{b}}$ of which can reasonably be compared with the one of propylamine, $\mathrm{pK}_{\mathrm{b}}=3.33$, making APTES a base slightly stronger than ammonia (and of course weaker than $\mathrm{NaOH}$ ). For these reasons, the effect of APTES on SL can reasonably be compared and discussed with respect to the $\mathrm{NaOH}$ and $\mathrm{NH}_{3}$ effects. Accordingly, SL3 with the lowest $\mathrm{NH}_{2}$ /SL ratio close to 2, behaves like a typical micelletemplated mesostructured material where pores are only accessible after surfactant removal with a narrow pore size distribution (after removal) centered at $4 \mathrm{~nm}$ is in agreement with the size of a sophorolipid micelle (about $4.5 \mathrm{~nm}$ ). ${ }^{16,17}$ In contrast, in SL2 and SL1, the $\mathrm{NH}_{2}$ content is much larger with respect to $\mathrm{SL}$ (molar ratios: $\mathrm{NH}_{2} / \mathrm{SL} \approx 5.5$ and 9.0, respectively) (Figure 4b). For this reason, a more complex interaction between the aminopropyl group and sophorolipids can be expected. 



a)

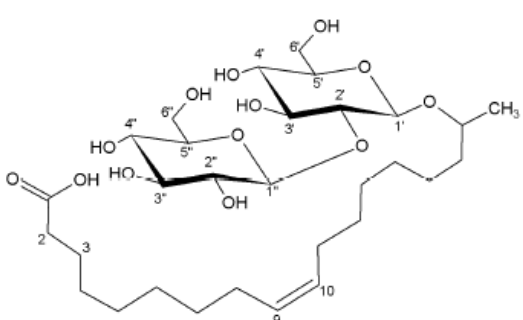

$$
\stackrel{\alpha}{\stackrel{\alpha}{\mathrm{C}}} \stackrel{\beta}{\mathrm{C}} \mathrm{H}_{2}-\stackrel{\beta}{\mathrm{C}} \mathrm{H}_{2}-\mathrm{CH}_{2} \mathrm{NH}_{2}
$$

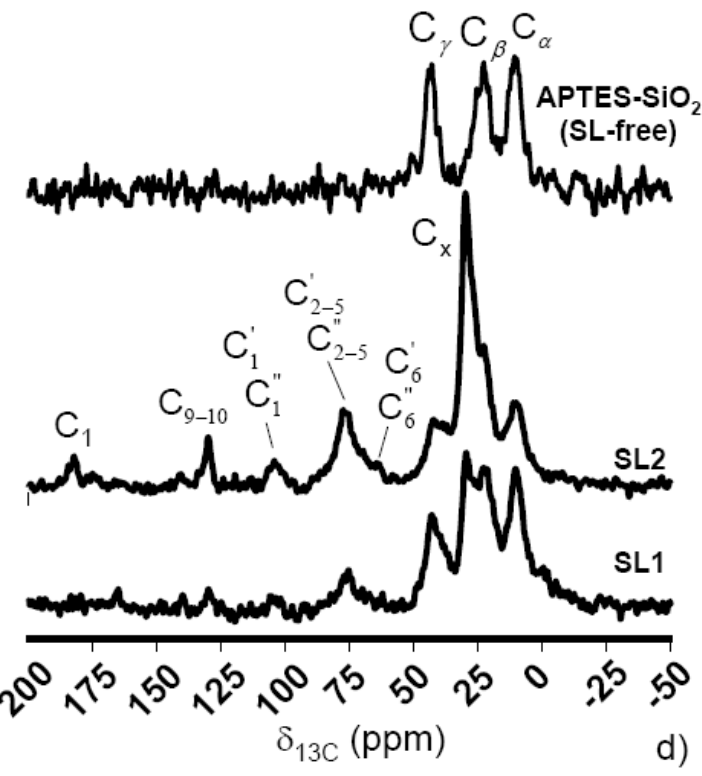

Figure 4 - (a) TGA curves; (b) $\mathrm{NH}_{2} / \mathrm{SL}$ molar ratio obtained from (N, C) elemental analysis (the contribution of the propyl groups has been subtracted from that of sophorolipids; (c) typical FT-IR spectra for SL1 and pure, silica-free, sophorolipids (SL) powder; (d) ${ }^{13} \mathrm{C}\left\{{ }^{1} \mathrm{H}\right\}$ CP-MAS solid state NMR

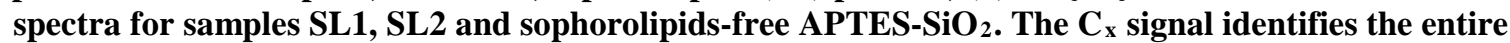
aliphatic chain $\left(\mathrm{C}_{4}-\mathrm{C}_{7}\right.$ and $\left.\mathrm{C}_{12}-\mathrm{C}_{16}\right)$

The ${ }^{13} \mathrm{C}$ NMR spectrum of the reference APTES-SiO 2 , sophorolipid-free, powder is shown in Figure 4d, displaying the typical fingerprint of the organosilane propyl carbons: $\delta=$ $10.7 \mathrm{ppm}, 23.4 \mathrm{ppm}$ and $43.7 \mathrm{ppm}$ for the $\alpha, \beta$ and $\gamma$ carbons, respectively (refer to Figure 4 for attribution). ${ }^{42}$ The spectra of SL2 and SL1 are also shown in Figure 4d, where the corresponding peak attribution for SL2 with respect to the SL molecule is presented on top of the spectrum, Hence it appears that the templating process does not affect the SL molecular structure. Indeed, the ${ }^{13} \mathrm{C}$ NMR spectra of SL2 and SL1 also contain the signals of the propyl group, that is easily identified by comparison with the reference sample. Noticeably, these signals are predominant in the SL1 spectra, in agreement with the elemental analysis. 


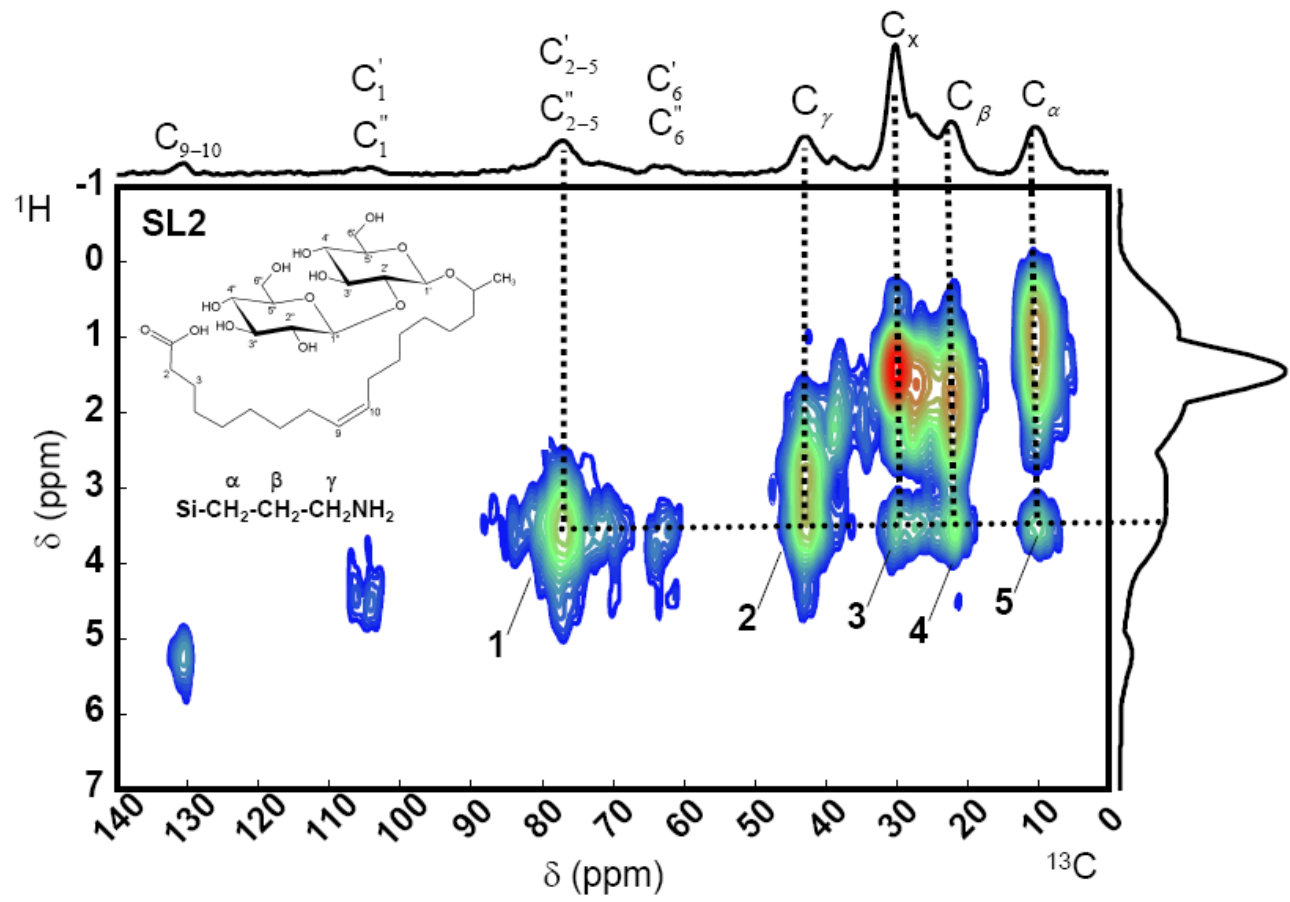

Figure 5 - 2D ${ }^{13} \mathrm{C}-{ }^{1} \mathrm{H}$ CP-MAS HETCOR experiment recorded on SL2 sample using a contact time, $t_{\mathrm{c}}=$ $0.5 \mathrm{~ms}$.

To demonstrate the proximity between SL and the silica network, and in particular between SL and the aminopropyl group, we ran a 2D ${ }^{1} \mathrm{H}-{ }^{13} \mathrm{C}$ HETeronuclear CORrelation (HETCOR) experiment, shown in Figure 5. This experiment is based on the dipolar coupling between ${ }^{1} \mathrm{H}$ and ${ }^{13} \mathrm{C}$, which is dependant on $1 / r^{3}$, where $r$ is the internuclear distance. One can thus probe inter-nuclear proximities. The 2D map in Figure 5 is dominated by cross-peaks that are directly related to the $\mathrm{CH}_{\mathrm{x}}$ chemical bond for all resonances, something expected for the selected short contact time $\left(\mathrm{t}_{\mathrm{c}}=0.5 \mathrm{~ms}\right)$. Nevertheless, the additional cross-peaks, numbered 1 through 5, deserve a specific attention. Cross-peak No.1 is due to the C-H bonds present in the sophorose head and in particular those related to carbons $C_{2-5}^{\prime}$ and $C^{\prime 2-5}$. Cross-peaks No.5, 4 and 2 indicate a specific through-space interaction between the $C_{\alpha}, C_{\beta}$ and $C_{\gamma}$ of the aminopropyl group with the H-groups of the sophorose head. Cross-peak No.3 states a through-space interaction between the sophorolipid aliphatic chain (here identified as $\mathrm{C}_{\mathrm{x}}$ and corresponding to the signals of $\mathrm{C}_{4}-\mathrm{C}_{7}$ and $\mathrm{C}_{12}-\mathrm{C}_{16}$ carbons) and the sophorose head. This experiment proves that SL and the aminopropyl group are very close in space and, in particular, that the $\mathrm{C}_{2}-\mathrm{C}_{5}$ carbons of the sophorose head are the more exposed to the propyl moiety. Meanwhile, parts of the aliphatic chain of SL interact with sophorose as well, thus suggesting its outward, silica-directed, bending. The outward bending of the end-chain moiety of sophorolipids was also hypothesized for sophorolipid micellar solutions alone based on neutron scattering arguments. ${ }^{18,25}$ It would have been very interesting to get information on 
the exact localization of the carbonyl group of sophorolipids but unfortunately its resonance cannot be detected in the 2D HETCOR map, neither at short (0.5 ms, Figure 5$)$ nor at long (10 ms, not shown here) contact time values.

Finally, we checked by infrared spectroscopy (Figure 4c) that the interaction between SL and the amino group is of electrostatic nature. In fact, the stretching vibration for the $\mathrm{COOH}$ group in pure SL at $1708 \mathrm{~cm}^{-1}$ is shifted to1542 $\mathrm{cm}^{-1}$, typical for the $\mathrm{COO}^{-}$form in SL1. Meanwhile, a signal at $1633 \mathrm{~cm}^{-1}$ identifies the $\mathrm{NH}_{3}{ }^{+}$antisymmetric bending. This establishes a charge matching between SL and APTES in the synthesis conditions. No evidence for amide I and amide II bands, that would indicate covalent interactions between the amino group and SL, could be observed. The scheme given in Figure 6 visualizes the local interactions between sophorolipids and the aminopropyl-modified silica according to the results obtained in the FT-IR and $2 \mathrm{D}{ }^{1} \mathrm{H}_{-}{ }^{13} \mathrm{C}$ HETCOR NMR experiment and matching the results found for AMS's. ${ }^{29}$



Figure 6 - Scheme of the local interaction between sophorolipids and aminopropyl-modified silica. FT-IR results are based on results shown in Figure 4c while solid state NMR is based on the results obtained in the HETCOR experiment described in Figure 5

\section{Driving forces behind the formation of SL1 and SL2 materials}

It is interesting to better understand how the interaction between APTES and SL drives the formation of porous silica spheres in SL1 and SL2. The most interesting features of these samples are their porogenic character obtained without calcination and their pore size distribution larger than the typical size of the sophorolipid molecule. 
The possible effects of $\mathrm{NH}_{2}$ are multifold, both on silica and on sophorolipids selfassembly. The first one takes into account the well-known ability of APTES to take part to the formation of spherical silica particles. ${ }^{34 b, 41,43,44}$ This process was suggested to occur via an aggregative pathway where primary particles fuse together to form larger objects. ${ }^{44,45}$ By this mechanism, the final particles generally show a certain surface roughness, ${ }^{44}$ but no specific porosity, ${ }^{34 \mathrm{~b}}$ a fact that is actually confirmed by our own experiments on the SL-free materials. Therefore, the presence of sophorolipids should interfere with the fusion process.

At equimolar $\mathrm{NH}_{2} / \mathrm{SL}$ ratios, we have already discussed the fact that sophorolipids form micelles that template silica. At higher ratios (SL1 and SL2 samples), SEM and TEM images in Figure 1 and Figure 2 show that silica spherical micrometer sized particles display an important roughness both at their outer surface (e.g., Figure 1d) and in their core (Figure 2a), a fact that nicely correlates with roughness estimation from nitrogen adsorption isotherms data. This result can then be related to the well-known aggregation model where particles below about $10 \mathrm{~nm}$ aggregate together to form a larger, condensed, silica spheres. ${ }^{45}$ From FTIR and solid state NMR we know that SL interacts with $\mathrm{NH}_{2}$ groups. Since it is known that APTES is highly concentrated at the particle surface, ${ }^{34 b, 44}$ one can reasonably make the hypothesis of the formation of SL-stabilized silica nanoparticles, the coalescence of which is partially hindered by the presence of sophorolipids, forming a porous network. A possible depletion mechanism could in fact induce the attraction between sophorolipids molecules, thus inducing colloidal attraction between silica nanoparticles, as described before for the SDS/Ludox system. ${ }^{46}$ The interparticle attraction for silica in the presence of a surfactant has also been described by Sharma et al. ${ }^{47}$ This picture eventually leads to the idea of a homogeneously SL-coated continuous silica network composed of fused primary particles.

Our second hypothesis consists of analyzing the effect of the excess of $\mathrm{NH}_{2}$ on the nature of the SL assemblies. In fact, we know from previous works ${ }^{17,18,25}$ that SL can form micrometersized networks under basic $\mathrm{pH}$ conditions so it becomes possible that silica is directly stabilized by such structures, which constitute the actual template. A similar hypothesis was emitted in the formation of large mesopores in sophorolipid-templated silica thin films under basic conditions. ${ }^{48}$

The last scenario consists into taking into account a possible phase separation mechanism driven by the strong interactions between sophorolipids and silica oligomers in analogy to what has been observed in many systems described by the group of Nakanishi. ${ }^{49}$ In these works, meso-macroporous silica gels are commonly obtained upon addition of organic additives (generally polymeric compounds and, in few cases, surfactants) to induce phase 
separation. For silica-based systems, mesoscale porosity is systematically obtained by removing the organic additives (surfactants and polymers) by calcination while macroporosity is generally obtained by the so-called "chemical cooling" effect, where the two-phase domain is influenced by both silica condensation and specific inorganic (silica) - organic (polymers, surfactants, co-solvents) composition of matter. The solvent excess is eventually removed by evaporation thus leaving open macroscale porosity. The mechanism, texture and final size of the pores in the final material largely vary according to the composition of the gel. For silica, pores reach the approximate dimensions of few microns, even if these may depend on the relative silica/additive composition. Small mesopores can also be obtained if a surfactant is employed. This is obviously not the case in this work, as we do not observe large macropores and mesopores have a broad size distribution up to several $\mathrm{nm}$.

The mechanism is slightly different for some specific metal oxides (metal center, $\mathrm{M}=\mathrm{Ti}, \mathrm{Al}$ ), the inorganic polymerization reactions of which are much faster than in silica-based systems. ${ }^{50,51}$ In this case, the gel is formed by the association of nanoscale primary particles, where braod-band mesoporosity is automatically generated without removing the organic additive. Nevertheless, the nature of the metal oxide/additive interactions and the additive/solvent role are far from being clear. According to the numerous data collected by Nakanishi et al. on silica, one should not expect porosity driven from the aggregation of primary particles, as seen for alumina aerogels and xerogels, ${ }^{51}$ but this is exactly what we do observe on SL1 and SL2 materials in this study. To account for this, we then must imagine such a strong interaction between SL and aminopropyl modified silica nanoparticles that eventually coalesce together and phase separate from the water solvent. Considering that both silica oligomers and sophorolipids are hydrophilic, the former can interact with condensing silicates both via the $\mathrm{COO}^{-}$and sophorose groups, thus leaving the aliphatic backbone oriented towards the water solution. In this case, silicate oligomers actually become slightly hydrophobic and can eventually undergo phase separation. Whether the interaction involves single sophorolipid molecules (as in the first hypothesis) or its micronic assemblies (as in the second hypothesis), which may be considered as polymer-like objects, is difficult to ascertain at this time. In addition, the fact that experiments are run at $\mathrm{T}=60^{\circ} \mathrm{C}$, followed by a treatment at $\mathrm{T}=100^{\circ} \mathrm{C}$, should not be neglected and a time-resolved study, from the moment of mixing the precursors until the final material, could help to better understand the origin of the porogenic effect.

\section{Conclusion}


Bioderived glycolipids have been used here as supramolecular templates for the synthesis of silica particles with broadband mesoporosity. These compounds, belonging to the family of acidic sophorolipids, have an accessible $\mathrm{COOH}$ group making them $\mathrm{pH}$-responding. In this work, we have exploited such a feature to promote the interaction with $\mathrm{NH}_{2}$-modified silica using a sol-gel reaction in water. Addition of the amino group via APTES is of paramount importance to promote the precipitation of a solid in solution, whereas a gel would be formed otherwise. By playing with the $\mathrm{NH}_{2} / \mathrm{SL}$ ratio it is possible to produce silica particles with different features. At low ratios, materials have no particular morphology and one need calcination to obtain a narrow pore size distribution centered at about $3 \mathrm{~nm}$, a value that is coherent with the molecular size of the initial sophorolipid.

At higher ratio, on the contrary, porous micrometer-sized spherical particles are formed, where the porosity is actually accessible without the classical calcination step and its size distribution ranges from $5 \mathrm{~nm}$ to $30 \mathrm{~nm}$. It is important to note that no additional compound (e.g., block copolymer, polymer, organic solvent, pore-swelling agent) has been added to the system to reach the pore size larger than $20 \mathrm{~nm}$ and as it is typically done in the literature on the synthesis of materials with large pores. If calcination is performed, only small pores (dp> $3 \mathrm{~nm}$ ) are formed and the $t$-plot analysis realized on nitrogen physisorption data shows that no microporosity is actually formed. These data are confirmed by high-resolution TEM and SEM-FEG images, that show the presence of both surface roughness (also confirmed by an advanced analysis of the physisorption data) and particle core porosity, which seem to derive from the aggregation of primary nanoparticles. The strong interaction between acidic sophorolipids and amino-modified silica is probed using FT-IR, which show the presence of $\mathrm{COO}^{-}$and amino groups but no amide bonds, thus suggesting the electrostatic nature of the interaction itself, and solid state NMR spectroscopy. The last technique is quite powerful as it demonstrates, via a 2D CP-MAS ${ }^{1} \mathrm{H}^{13} \mathrm{C}$ HETCOR experiment at low contact times $\left(\mathrm{t}_{\mathrm{c}}=0.5\right.$ $\mathrm{ms}$ ), the local proximity between the aminopropyl group and the disaccharide (sophorose), which constitute the hydrophilic head of sophorolipids. In terms of the type of templating mechanism that could take place, we propose several hypotheses, which span from a direct template by the supramolecular assemblies that SL form under basic conditions to a possible spinoidal decomposition or a combination of both.

\section{Acknowledgement}


The research leading to these results has received funding from the European Community's Seventh Framework Programme (FP7/2007-2013) under Grant Agreement $\mathrm{n}^{\circ}$ Biosurfing/289219. Dr. Cédric Boissière and Dr. Lionel Nicole (Laboratoire de Chimie de la Matière Condensée de Paris, Paris, France) are kindly acknowledged for their help on nitrogen adsorption/desorption analysis and t-plot data treatment. Caroline Koussou (LCMCP, Pairs) is kindly acknowledged for her experimental help. Guillaume Laurent (Laboratoire de Chimie de la Matière Condensée de Paris, Paris, France) is kindly acknowledged for his help on NMR experiments. David Montero (IMPC, Paris, France) is acknowledged for his help on SEM-FEG experiments.

\section{Supporting Information}

Figure S1 - Identification of the optimal $t=\left(\frac{P}{P_{0}}\right)$ expression; Figure S2 - t-plots roughness studies; Figure S3 - Comparison between the $\mathrm{N}_{2}$ adsorption-desorption isotherms of assynthesized and calcined (a) SL1 and (b) SL2 samples; Figure S4 - Quantitative single pulse ${ }^{29} \mathrm{Si}$ MAS NMR spectra. This information is available free of charge via the Internet at http://pubs.acs.org/.

\section{References}

(1)Qian, K.K.; Bogner, R.H. Application of mesoporous silicon dioxide and silicate in oral amorphous drug delivery systems J. Pharm. Sci. 2012, 101, 444-463

(2)Lee, J. E.; Lee, N.; Kim, T.; Kim, J.; Hyeon, T. Multifunctional Mesoporous Silica Nanocomposite Nanoparticles for Theranostic Applications Acc. Chem. Res. 2011, 44, 893-902

(3)Slowing, I. I.; Vivero-Escoto, J. L.; Trewyn, B. G.; Lin, V. S. Y. Mesoporous silica nanoparticles: structural design and applications J. Mater. Chem. 2010, 20, 7924-7937

(4)Sel, O.; Kuang, D.; Thommes, M.; Smarsly, B. Principles of Hierarchical Meso- and Macropore Architectures by Liquid Crystalline and Polymer Colloid Templating Langmuir 2006, 22, 2311-2322

(5)Fujita, S.; Nakano, H.; Ishii, M.; Nakamura, H.; Inagaki, S. Preparation of hierarchical porous silica and its optical property Micro. Mesop. Mater. 2006, 96, 205-209

(6)Chiu, J. J.; Pine, D. J.; Bishop, S. T.; Chmelka, B. F. Friedel-Crafts alkylation properties of aluminosilica SBA-15 meso/macroporous monoliths and mesoporous powders J. Catal. 2004, 221, 400-412

(7)Beck, J. S.; Vartuli, J. C.; Roth, W. J.; Leonowicz, M. E.; Kresge, C. T.; Schmitt, K. D.; Chu, C. T. W.; Olson, D. H.; Sheppard, E. W. A new family of mesoporous molecular sieves prepared with liquid crystal templates J. Am. Chem. Soc. 1992, 114, 10834

(8)Huo, Q.; Margolese, D. I.; Stucky, G. D. Surfactant Control of Phases in the Synthesis of Mesoporous SilicaBased Materials Chem. Mater. 1996, 8, 1147

(9) a) Kresge, C. T.; Leonowicz, M. E.; Roth, W. J.; Vartuli, J. C.; Beck, J. S. Nature 1992, 359, 710; b) Huo, Q.; Margolese, D. I.; Clesla, U.; Feng, P.; Gier, T. E.; Sieger, P.; Leon, R.; Petroff, P. M.; Schueth, F.; Stucky, G. D. Generalized synthesis of periodic surfactant/inorganic composite materials Nature 1994, 368, 317

(10)Zhao, D.; Feng, J.; Huo, Q.; Melosh, N.; Fredrickson, G. H.; Chmelka, B. F.; Stucky, G. D. Triblock Copolymer Syntheses of Mesoporous Silica with Periodic 50 to 300 Angstrom Pores Science 1998, 279, 548 (11)Innocenzi, P.; Malfatti, L.; Soler-Illia, G. J. A. A. Hierarchical Mesoporous Films: From Self-Assembly to Porosity with Different Length Scales Chem. Mater., 2011, 23, 2501-2509

(12)Yang, P.; Deng, T.; Zhao, D.; Feng, P.; Pine, D.; Chmelka, B. F.; Whitesides, G. M.; Stucky, G. D. Hierarchically Ordered Oxides Science, 1998, 282, 2244-2246 
(13)Baccile, N.; Reboul, J.; Blanc, B.; Coq, B.; Lacroix-Desmazes, P.; In, M.; Gérardin, C. Ecodesign of Ordered Mesoporous Materials Obtained with Switchable Micellar Assemblies Angew. Chem. Int. Ed. 2008, 120, 8561-8565

(14)Che, S.; Garcia-Bennett, A. E.; Yokoi, T.; Sakamoto, K.; Kunieda, H.; Terasaki, O.; Tatsumi, T. A novel anionic surfactant templating route for synthesizing mesoporous silica with unique structure Nat. Mater. 2003, 2, 801-805

(15)Gérardin, C.; Reboul, J. ; Bonne, M.; Lebeau, B. Ecodesign of ordered mesoporous silica materials Chem. Soc. Rev. 2013, 42, 4217-4255

(16)Baccile, N.; Nassif, N.; Malfatti, L. ; Van Bogaert, I. N. A. ; Soetaert, W.; Pehau-Arnaudet, G.; Babonneau, F. Sophorolipids: a yeast-derived glycolipid as greener structure directing agents for self-assembled nanomaterials Green Chem. 2010, 12, 1564-1567

(17)Baccile, N.; Babonneau, F.; Jestin, J.; Pehau-Arnaudet, G.; Van Bogaert, I. N. A. Unusual, pH-Induced, SelfAssembly Of Sophorolipid Biosurfactants ACS Nano 2012, 6, 4763-4776

(18)Baccile, N. ; Pedersen, J. S.; Pehau-Arnaudet, G.; Van Bogaert, I. N. A. Surface charge of acidic sophorolipid micelles: effect of base and time Soft Matter 2013, 9, 4911-4922

(19) a) Rau, U.; Hammen, S.; Heckmann, R.; Wray, V.; Lang, S. Sophorolipids: a source for novel compounds Ind. Crops Prod. 2001, 13, 85-92; b) Tulloch, A. P.; Hill, A.; Spencer, J. F. T. Structure and reactions of lactonic and acidic sophorosides of 17-hydroxyoctadecanoic acid Canad. J. Chem. 1968, 46, 3337-3351; c) Asmer, H.-J.; Lang, S.; Wagner, F.; Wray, V. Microbial production, structure elucidation and bioconversion of sophorose lipids J. Am. Oil. Chem. Soc. 1988, 65, 1460-1466

(20)Develter, D.W.G.; Fleurackers, S. J. J. Surfactants from Renewable Resources, pp.213-238, 2010, John Wiley \& Sons, Ltd, West Sussex, UK

(21) a) Maingault, M. Use of sophorolipids and cosmetic and dermatological compositions, WO/1995/034282A; b) Van Bogaert, I. N. A.; Saerens, K.; De Muynck, C.; Develter, D.; Soetaert, W.; Vandamme, E. J. Microbial production and application of sophorolipids Appl. Microbiol. Biotechnol. 2007, 76, 23-34; c) Shete, A. M.; Wadhawa, G.; Banat, I. M.; Chopade, B. A. Mapping of patents on bioemulsifier and biosurfactant: A review J. Sci. Ind. Res. 2006, 65, 91-111

(22)Shah, V.; Badia, D.; Ratsep, P. Sophorolipids Having Enhanced Antibacterial Activity Antimicrob. Agents Chemother. 2007, 51, 397

(23)Fu, S. L.; Wallner, S. R.; Bowne, W. B.; Hagler, M. D.; Zenilman, M. E.; Gross, R.; Bluth, M. H. Sophorolipids and their derivatives are lethal against human pancreatic cancer cells. J. Surg. Res., 2008 148, 77 82

(24) a) Singh, S.; Patel, P.; Jaiswal, S.; Prabhune, A. A.; Ramana, C. V.; Prasad, B. L. V. A direct method for the preparation of glycolipid-metal nanoparticle conjugates: sophorolipids as reducing and capping agents for the synthesis of water re-dispersible silver nanoparticles and their antibacterial activity New J. Chem. 2009, 33, 646652; b) Kasture, M.; Singh, S.; Patel, P.; Joy, P. A.; Prabhune, A. A.; Ramana, C. V.; Prasad, B. L. V. Multiutility Sophorolipids as Nanoparticle Capping Agents: Synthesis of Stable and Water Dispersible Co Nanoparticles Langmuir 2007, 23, 11409-11412; c) Dhar, S.; Reddy, E. M.; Prabhune, A.; Pokharkar, V.; Shiras, A.; Prasad, B. L. V. Cytotoxicity of sophorolipid-gellan gum-gold nanoparticle conjugates and their doxorubicin loaded derivatives towards human glioma and human glioma stem cell lines Nanoscale 2011, 3, 575-580; d) Baccile, N.; Noiville, R.; Stievano, L.; Van Bogaert, I. Sophorolipids-functionalized iron oxide nanoparticles Phys. Chem. Chem. Phys. 2013, 15, 1606

(25)Penfold, J.; Chen, M.; Thomas, R. K.; Dong, C.; Smyth, T. J. P.; Perfumo, A.; Marchant, R.; Banat, I. M.; Stevenson, P.; Parry, A.; Tucker, I.; Grillo, I. Solution Self-Assembly of the Sophorolipid Biosurfactant and Its Mixture with Anionic Surfactant Sodium Dodecyl Benzene Sulfonate Langmuir 2011, 27, 8867-8877

(26)Dhasaiyan, P.; Banerjee, A.; Visaveliya, N.; Prasad, B. L. V. Influence of the Sophorolipid Molecular Geometry on their Self-Assembled Structures Chem. Asian J. 2013, 8, 369-372

(27)Fontecave, T.; Baccile, N.; Sanchez, C.; Plou, F.; Boissière, C. Chem. Mater., accepted, DOI:

$10.1021 / \mathrm{cm} 401807 \mathrm{~m}$

(28)Baccile, N.; Laurent, G.; Bonhomme, C.; Innocenzi, P.; Babonneau, F. Solid-state NMR characterization of the surfactant-silica interface in templated silicas : acidic versus basic conditions. Chem. Mater. 2007, 19, 13431354

(29)Han, L.; Che, S. Anionic surfactant templated mesoporous silicas (AMSs) Chem. Soc. Rev. 2013, 42, 37403752

(30)Atluri, R.; Hedin, N.; Garcia-Bennett, A. E. Nonsurfactant Supramolecular Synthesis of Ordered Mesoporous Silica J. Am. Chem. Soc. 2009, 131, 3189-3191

(31) http://rsbweb.nih.gov/ij/

(32) Hediger, S.; Meier, B. H.; Kurur, N. D.; Bodenhausen, G.; Ernst, R.R. NMR cross polarization by adiabatic passage through the Hartmann-Hahn condition (APHH) Chem. Phys. Lett. 1994, 223, 283 
(33) Hediger, S.; Meier, B. H.; Ernst, R. R., Adiabatic passage Hartmann-Hahn cross polarization in NMR under magic angle sample spinning Chem. Phys. Lett. 1995, 240, 449

(34) a) Wu, Z.; Xiang, H.; Kim, T.; Chun, M.-S.; Lee, K. Surface properties of submicrometer silica spheres modified with aminopropyltriethoxysilane and phenyltriethoxysilane J. Coll. Interf. Sci. 2006, 304, 119-124; b) van Blaaderen, A.; Vrij, A. Synthesis and Characterization of Monodisperse Colloidal Organo-silica Spheres $J$. Coll. Interf. Sci. 1993, 156, 1-18

(35)Rouquerol, F.; Rouquerol, J.; Sing, K. Adsorption by Powders \& Porous Solids: Principles, Methodology and Applications, section 7.5, p. 204, 1999, Academia Press, London, UK

(36)Zhao, D.; Huo, Q.; Feng, J.; Chmelka, B. F.; Stucky, G. D. Nonionic Triblock and Star Diblock Copolymer and Oligomeric Surfactant Syntheses of Highly Ordered, Hydrothermally Stable, Mesoporous Silica Structures $J$. Am. Chem. Soc. 1998, 120, 6024-6036

(37)Sayari, A.; Liu, P.; Kruk, M.; Jaroniec, M. Characterization of Large-Pore MCM-41 Molecular Sieves Obtained via Hydrothermal Restructuring Chem. Mater. 1997, 9, 2499-2506

(38)Kruk, M.; Jaroniec, M.; Sayari, A. Application of Large Pore MCM-41 Molecular Sieves To Improve Pore Size Analysis Using Nitrogen Adsorption Measurements Langmuir 1997, 13, 6267-6273

(39)Drisko, G. L.; Zelcer, A.; Luca, V.; Caruso, R. A.; Soler-Illia, G. J. de A. A. One-Pot Synthesis of Hierarchically Structured Ceramic Monoliths with Adjustable Porosity Chem. Mater. 2010, 22, 4379-4385

(40)Prouzet, E.; Boissière, C.; Kim, S. S.; Pinnavaia, T. J. Roughness of mesoporous silica surfaces deduced from adsorption measurements Microp. Mesop. Mater. 2009, 119, 9-17

(41)Ottenbrite, R. M.; Wall, J. S.; Siddiqui, J. A. Self-Catalyzed Synthesis of Organo-Silica Nanoparticles J. Am. Ceram. Soc. 2000, 83, 3214 - 3215

(42)Albert, K.; Pfleiderer, B.; Bayer, E.; Schnabel, R. Characterization of chemically modified glass surfaces by 13C and 29Si CP/MAS NMR spectroscopy J. Coll. Interface Sci. 1991, 142, 35-40

(43)Rahman, I. A.; Jafarzadeh, M.; Sipaut, C. S. Synthesis of organo-functionalized nanosilica via a cocondensation modification using $\gamma$-aminopropyltriethoxysilane (APTES) Ceramics Int. 2009, 35, 1883-1888

(44)Chen, S.; Hayakawa, S.; Shirosaki, Y.; Fujii, E.; Kawabata, K.; Tsuru, K.; Osaka, A. Sol-Gel Synthesis and Microstructure Analysis of Amino-Modified Hybrid Silica Nanoparticles from Aminopropyltriethoxysilane and Tetraethoxysilane J. Am. Ceram. Soc. 2009, 92, 2074

(45)Bogush, G. H.; Zukoski IV, C. F. Uniform silica particle precipitation: An aggregative growth model J. Coll. Interf. Sci. 1991, 142, 19-34

(46)Kline, S. R.; Kaler, E. W. Interactions in binary mixtures: Partial structure factors in mixtures of sodium dodecyl sulfate micelles and colloidal silica J. Chem. Phys. 1996, 105, 3813-3822

(47)Sharma, K. P.; Aswal, V. K.; Kumaraswamy, G. Adsorption of Nonionic Surfactant on Silica Nanoparticles: Structure and Resultant Interparticle Interactions J. Phys. Chem. B 2010, 114, 10986-10994

(48)Baccile, N.; Fontecave, T.; Boissière, C.; Van Bogaert, I. N. A. Hierarchical Porosity in Silica Thin Films by a One-Step Templating Strategy Using a Stimuli-Responsive Bioderived Glycolipid J. Phys. Chem. C 2013,

$117,23899-23907$

(49)Nakanishi, K.; Tanaka, N. Sol-Gel with Phase Separation. Hierarchically Porous Materials Optimized for High-Performance Liquid Chromatography Separations Acc. Chem. Res. 2007, 40, 863-873

(50)Hasegawa, G.; Kanamori, K.; Nakanishi, K.; Hanada, T. Facile Preparation of Hierarchically Porous TiO2 Monoliths J. Am. Ceram. Soc. 2010, 93, 3110-3115

(51)Tokudome, Y.; Nakanishi, K.; Kanamori, K.; Fujita, K.; Akamatsu, H.; Hanada, T. Structural characterization of hierarchically porous alumina aerogel and xerogel monoliths J. Coll. Interf. Sci. 2009, 338, 506-513 